\title{
Supplementary information for Scheme for calculation of multi-layer cloudiness and precipitation for climate models of intermediate complexity
}

A.V. Eliseev, D. Coumou, A.V. Chernokulsky, V. Petoukhov, and S. Petri

\section{References}

Mace, G., Zhang, Q., Vaughan, M., Marchand, R., Stephens, G., Trepte, C., and Winker, D.: A description of hydrometeor layer occurrence statistics derived from the first year of merged Cloudsat and CALIPSO data, J. Geophys. Res., 114, D00A26, doi:10.1029/2007JD009755, 2009. 


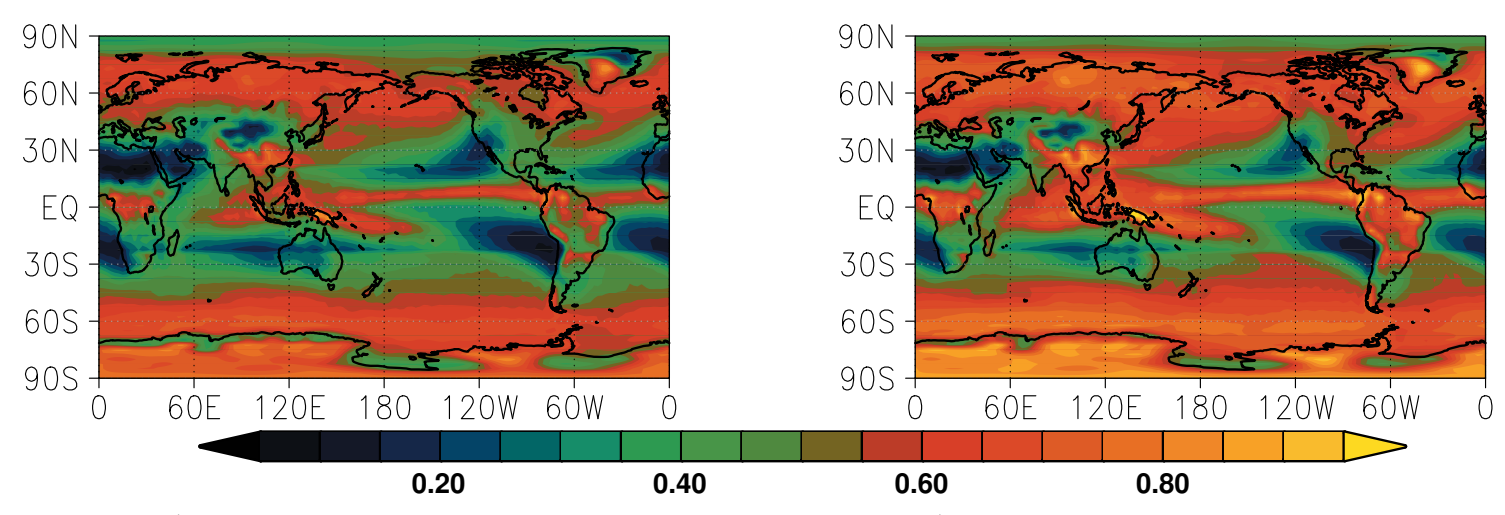

c) initial, mid-level

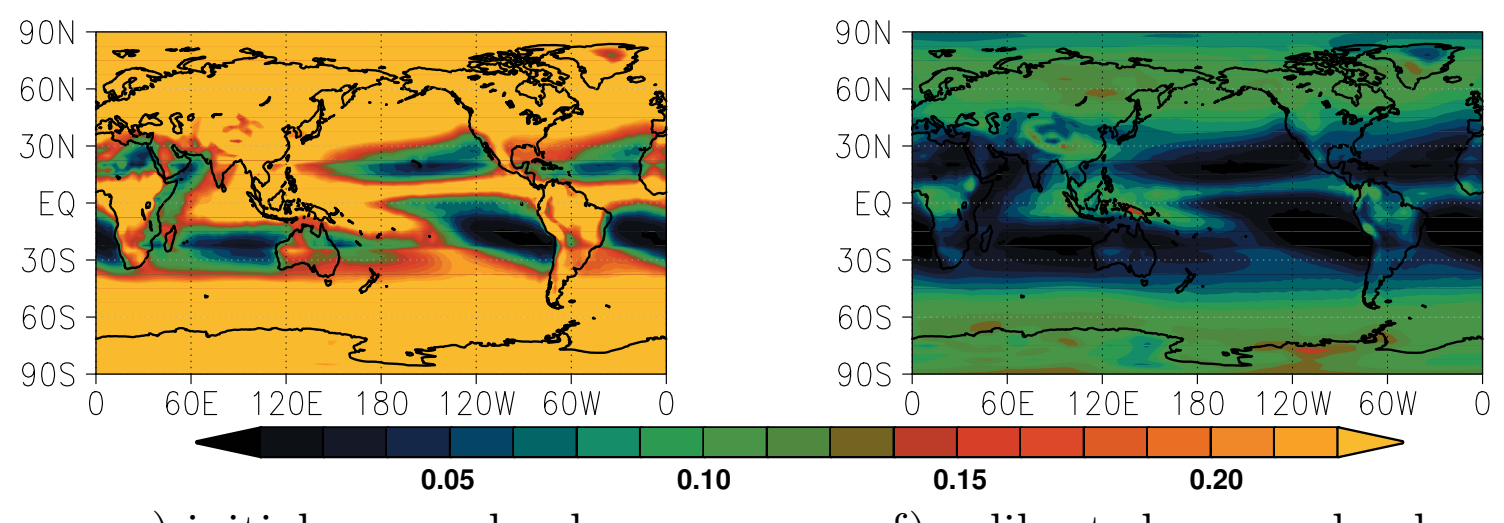

e) initial, upper-level

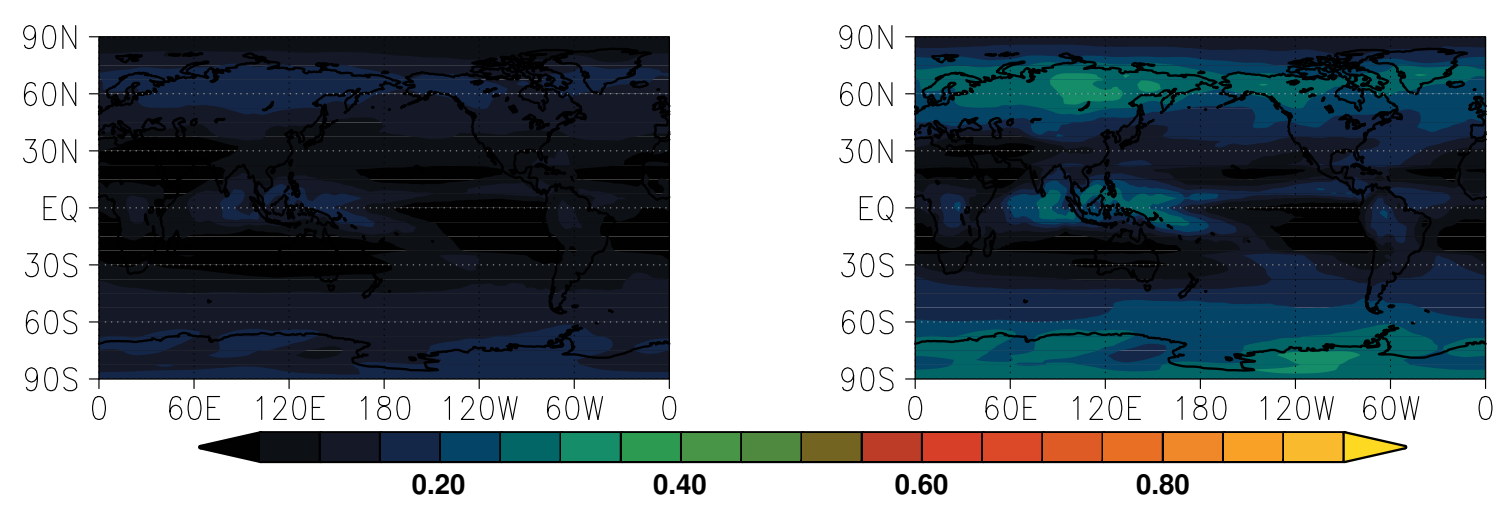

Figure S1: Annual mean low-level cloud amount $c_{l} \equiv c_{s l}+c_{c o}$ (a and b), midlevel cloud amount $c_{m} \equiv c_{s m}$ (c and d), and upper-level cloud amount $c_{h} \equiv c_{s h}$ (e and f) for the model versions with initial (a, c, and e) and calibrated (b, d, and $\mathrm{f}$ ) parameter sets. The units are fractions.

This is a duplicate for Fig. 5 of the main text but redrawn to be compatible to relevant Figures from (Mace et al., 2009) (see also Fig. S2). 
a)

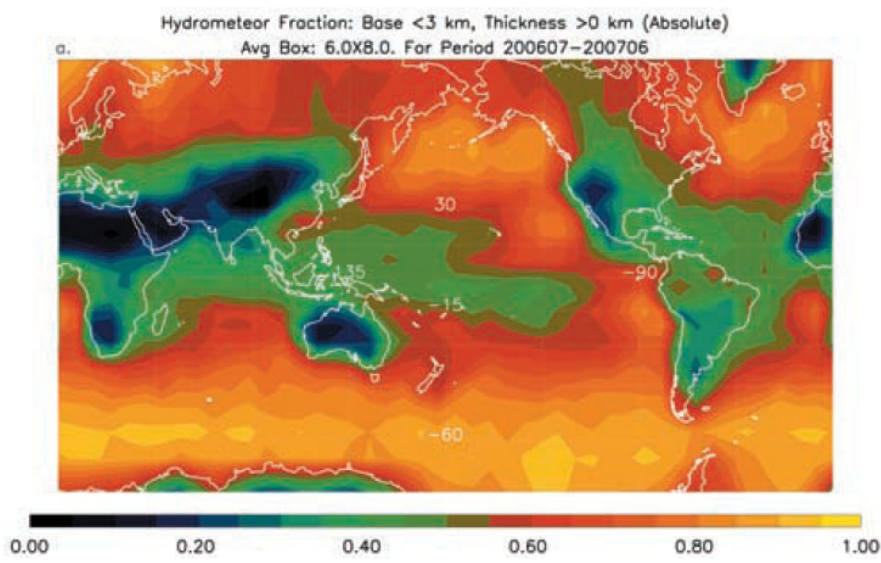

b)

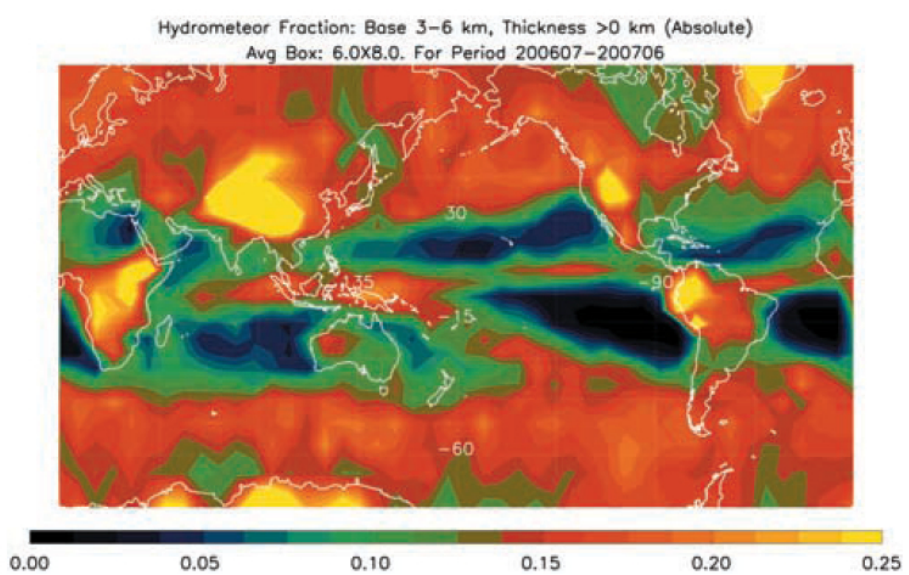

c)

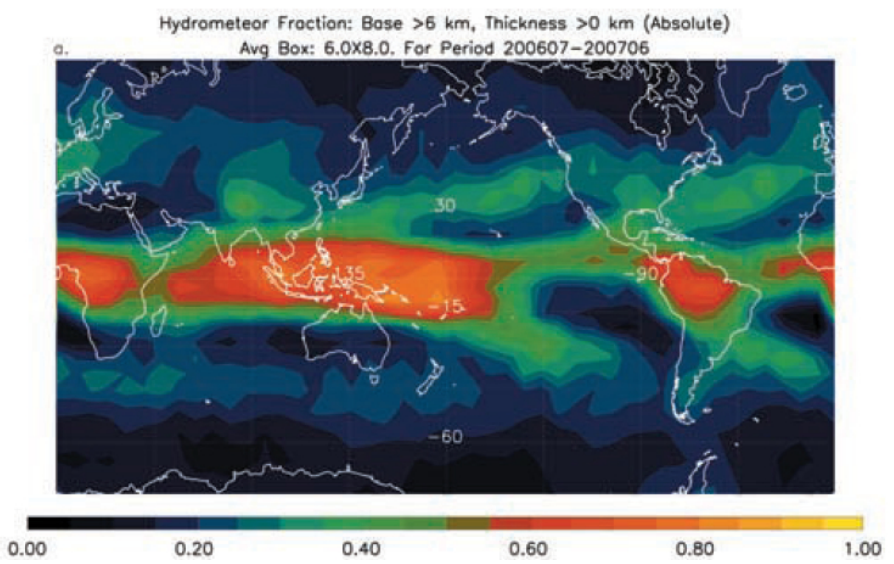

Figure S2: Figures 10a, 11, and 12a from (Mace et al., 2009) (a, b, and c correspondingly). The plots are reproduced with permission from John Wiley and Sons Inc. (license number 3144290033498). 